\title{
PREVALENCE OF ANTISOCIAL BEHAVIOUR AMONG CHILDREN AND ADOLESCENTS IN A COMMUNITY SAMPLE - A CROSS-SECTIONAL STUDY IN SOUTH KARNATAKA, INDIA
}

\author{
Bhuvana C. Revappala1, Jaya Bharathi², Revathi K. Gowda ${ }^{3}$ \\ ${ }^{1}$ Consultant Psychiatrist, Department of Psychiatry, Wellspring Mind Care, Sharavathinagara, Shimoga. \\ ${ }^{2}$ Psychologist, Department of Psychiatry, Wellspring Mind Care, Sharavathinagara, Shimoga. \\ ${ }_{3}^{3}$ Assistant Doctor, Department of Psychiatry, Wellspring Mind Care, Sharavathinagara, Shimoga.
}

ABSTRACT
BACKGROUND
Children and adolescents involving in antisocial behaviour is one of the strongest predictors for development of antisocial
personality disorder in adults where a rapid cognitive and physical development occurs during that stage of life. Even though
knowing that antisocial behaviour is highly problematic to society due to disruption of societal norms, prevalence of this behaviour
in the community is not known.
$\quad$ Aim is to estimate the prevalence of antisocial behaviour among children and adolescent age groups.

Aim is to estimate the prevalence of antisocial behaviour among children and adolescent age groups.

\section{MATERIALS AND METHODS}

A total of 1026 participants, of both sexes, children and adolescents of age 6-18 years, from the educational institution of Shimoga district, where all the parents who were advised to come to the school and get interviewed by using child behaviour check list [CBCL (6-18 years)] in order to assess the antisocial behaviour among children and adolescent age groups; along with selfconstructed questionnaires to assess personal bio-data and factors responsible for these behaviours. $\mathrm{P}<0.05$ was considered as statistically significant.

\section{RESULTS}

The overall prevalence of antisocial behaviour from both age groups was $10.43 \%$ and males had higher prevalence of antisocial behaviour compared to their female counterparts $(\mathrm{p}<0.05)$. The most prevalent antisocial behaviour was vehicle related nuisances (31.25\%) followed by criminal damages (20.83\%). Differences in causal factors among the genders were significant.

\section{CONCLUSION}

Identifying the factors associated with antisocial behaviour among children and adolescents is critical for developing effective preventive strategies. Early intervention will minimise the risk of progression to more serious criminal behaviour later in life. The study concluded that much antisocial behaviour exists among children and adolescents in school students. These behaviours were found to be significantly associated with the respondents' gender, parents' economic status and parenting style $(\mathrm{P}<0.05)$.

\section{KEYWORDS}

Antisocial Behaviour, Criminality, Children, Adolescents, Violent Behaviour.

HOW TO CITE THIS ARTICLE: Revappala BC, Bharathi J, Gowda RK. Prevalence of antisocial behaviour among children and adolescents in a community sample - A cross-sectional study in South Karnataka, India. J.Evolution Med. Dent. Sci. 2016;5(87): 6492-6497, DOI: $10.14260 /$ jemds/2016/1468

\section{BACKGROUND \\ There has been a significant increase in the prevalence of antisocial behaviour (ASB) committed by the children and adolescents worldwide during the last half of the twentieth century, and the cost (Anderson 1999) of youth ASB within the United States has been estimated to exceed one trillion dollars. ${ }^{1}$ Behaviour is considered as abnormal or antisocial if it is uncommon, different from the norms and doesn't conform to what society expects. ${ }^{2} \mathrm{~A}$ particular behaviour is not acceptable or is antisocial if any of these three criteria are seen; the behaviour does not allow a person to function effectively with others as a member of society, the behaviour}

Financial or Other, Competing Interest: None

Submission 05-10-2016, Peer Review 22-10-2016,

Acceptance 24-10-2016, Published 29-10-2016.

Corresponding Author:

Dr. Bhuvana C. Revappala,

Consultant Psychiatrist

Department of Psychiatry,

Wellspring Mind care,

Sharavathinagara, Shimoga.

E-mail: doc.barbie@yahoo.in

DOI: $10.14260 /$ jemds/2016/1468 that does not permit the person to meet his or her own needs and the behaviour having a negative effect on the wellbeing of others. However, young people are segregated from adult society and such segregation serves as an important contribution to antisocial behaviour by teenagers. ${ }^{3}$

Period of adolescence and child age are the most crucial period in the life of human beings. The adolescent is eager to learn new experiences, to find new relationships, to examine the inner strength and fathom the strength of inner ability. They typically display no regards for the moral of ethical rules of the society or the rights of the others, manipulating people and situation for their own benefits. They display little guilt when they have injured someone else and in spite of understanding that they may have caused a person some harm they feel no remorse. 4,5

Antisocial people are unable to stand frustration and they are impulsive. These people can steal, lie, and cheats others. They often have unusually good social skill and their charm appearance allow them to convince others to comply with their wishes.6,7 These behaviours; however, are common among juvenile and peculiar to adolescents. According to the study by Dryfoos (1990), between $35 \%-40 \%$ of all boys 
growing up in an urbanised area will be arrested before their $18^{\text {th }}$ birthday. ${ }^{8}$ Some of these antisocial behaviours are traits which run in families. Family management practices such as marital breakdown, different caretakers, harsh and inconsistent discipline or multiple mothering in early childhood are important factors in developing aggressive and antisocial behaviour in adolescents later in life.

Antisocial behaviour is assumed to have resorted from faulty or inappropriate learning behaviour which consists of combination of learned association combined into ever larger chunks. According to Bandura (1997), Loeber (1990), and Stouthamer-Loeber (1986), people behave aggressively because of behaviour which they learn vicariously from watching others especially their peers. Behaviour is motivated by mental processes which individuals are often aware.2,6

The rate of increase in antisocial behaviour in the society is alarming (Loeber, 1990; Flanagan, 1987) and is evidenced by the number of people who die of suicide, rape, murder, disease, sexually transmitted diseases like AIDS. Alcoholism, drug abuse, smoking, suicide (Loeber 1990; Bell, 1986) 2,6 $^{2,}$ and others such as rape, cultism, prostitution, kidnapping, ritual are all antisocial behaviours which are traceable mostly from families with poor economic background, children from unstable family background (Ary et al 1999) or from children who have experienced major negative life events such as death of parents, children with frequent hassles of everyday life and frustration (Nwankwo, 2006).8,9 Antisocial behaviours are not restricted to males alone but have been found to be prevalent among adolescent girls also (Robins, 1986; Rutter and Giller, 1983). However, antisocial behaviours have been consistently reported to have come from environments characterised by parental rejection, permissiveness, aggression, lack of parental care, a low level of parental expectation, use of physical and painful punishment (Bandura, 1977; Ary et al; 1999a, b; MacDonald, 1985), unfavourable family relationships, (Ary et al 1999a, b) biological and physical changes, social expectation, social acceptance, fashion, inferiority feeling, pride, rebellion against parents, authorities and elders, struggle to achieve independence from family, and career choice.10,11,12

Prevalence rates of antisocial behaviour ultimately depend on the type of incident being examined, geographical location, cultural factors, family characteristics, socioeconomic setting, sampling procedure and diagnostic criteria used (Iloeje, 1992; Boyle et al, 1996). About 30\% and $45 \%$ of general practice child consultations and community child health referrals are for behavioural disturbances (NICE guidelines, 2013). It has been reported to be as high as 10$26 \%$ in both developed and developing countries (Abiodun, 1993; Rutter, 1973).13

To this end, the researchers were motivated to ascertain the prevalence and predictors of antisocial behaviours among children and adolescents in south Karnataka, which is seemingly the first to study in India as there were nil/negligible studies in this area. The study has sought to address the following objectives:

To determine the prevalence of antisocial behaviours among children and adolescents.

To ascertain the most prevalent or common form of antisocial behaviour among children and adolescents in this area.
To determine the factors responsible for the prevalence of antisocial behaviours among children and adolescents.

\section{MATERIALS AND METHODS \\ Source of Sample}

In this present study, data were collected from the educational institution which consists of schools of all the grades including pre-university (LKG-12th class) college at Shimoga district. The process was facilitated by assistance provided by the school teacher volunteers who were acquainted with the nature of the study, and the sample under consideration. Care was taken not to interrupt the curriculum of the school and participants were told about the purpose of the study, confidentiality, and anonymity was reiterated. The study was discussed in detail with the school authorities and permission was sought for conducting the research. Direct interview has been done for the participants (Parents) by using CBCL for the age group of 6-18 years. Each participant was interviewed separately in a private room.

Each parent/caregiver has been advised and convinced to co-operate for interview, not to manipulate at any point with the questionnaire during interviewing which might result in study bias and to maintain confidentiality with their coparticipants. Informed consent has been taken from each participant. All participants were given refreshments after the completion of the questionnaires.

\section{Sample Size}

Out of the total 1054 students, only 960 students' parents attended interview, others did not come due to some reasons.

\section{Age Group}

5-18 years of either sex. Informed consent was obtained from all the participants who were included in the study. Other sociodemographic details like education level, occupation, income, joint or nuclear family of all the participants has been collected.

\section{Statistical Method}

Chi-square test was used. A p-value of $<0.05$ was considered as statistically significant. Outcome of the study was analysed using SPSS software-19 version.

\section{Tools \\ 1. CBCL (6-18 Years $)^{14,15}$ \\ 2. DSM-V TR 16}

\section{CCMS-Child behaviour check list (6-18 Years)}

The Child Behaviour Checklist (CBCL) is a widely used method of identifying problematic behaviour among children and adolescents. It is one of the most widely used tools in both research and clinical practice for youth.

Problems are identified by a respondent who knows the child well, usually a parent or other caregiver. There are two versions of the checklist for caregivers, depending on the age of the youth. The preschool checklist (CBCL/11/2-5) is intended for use with children aged 18 months to 5 years. The school-age version (CBCL/6-18) is for children aged 6 to 18 years. The first page records demographic information and ratings of positive behaviours, academic functioning (for the school aged version), and social competence. The last two pages list common behaviour problems. Responses are 
recorded on a Likert scale: $0=$ Not True, $1=$ Somewhat or Sometimes True, 2=Very True or Often True.

DSM-V TR-Diagnostic and Statistical Manual of Mental Disorders, 5th edition. 12.

\section{DSM-V Headed as}

i. Adult Antisocial Behaviour [V71.01 (Z72.811)].

ii. Child or Adolescent Antisocial Behaviour [V71.02 (Z72.810)].

\section{RESULTS}

Flowchart of Respondents
We have considered second category, that has been used when the focus of clinical attention is antisocial behaviour in a child or adolescent that is not due to a mental disorder (e.g., intermittent explosive disorder, conduct disorder).

ICD-10 has not mentioned any specific regarding child or adolescent antisocial behaviour.

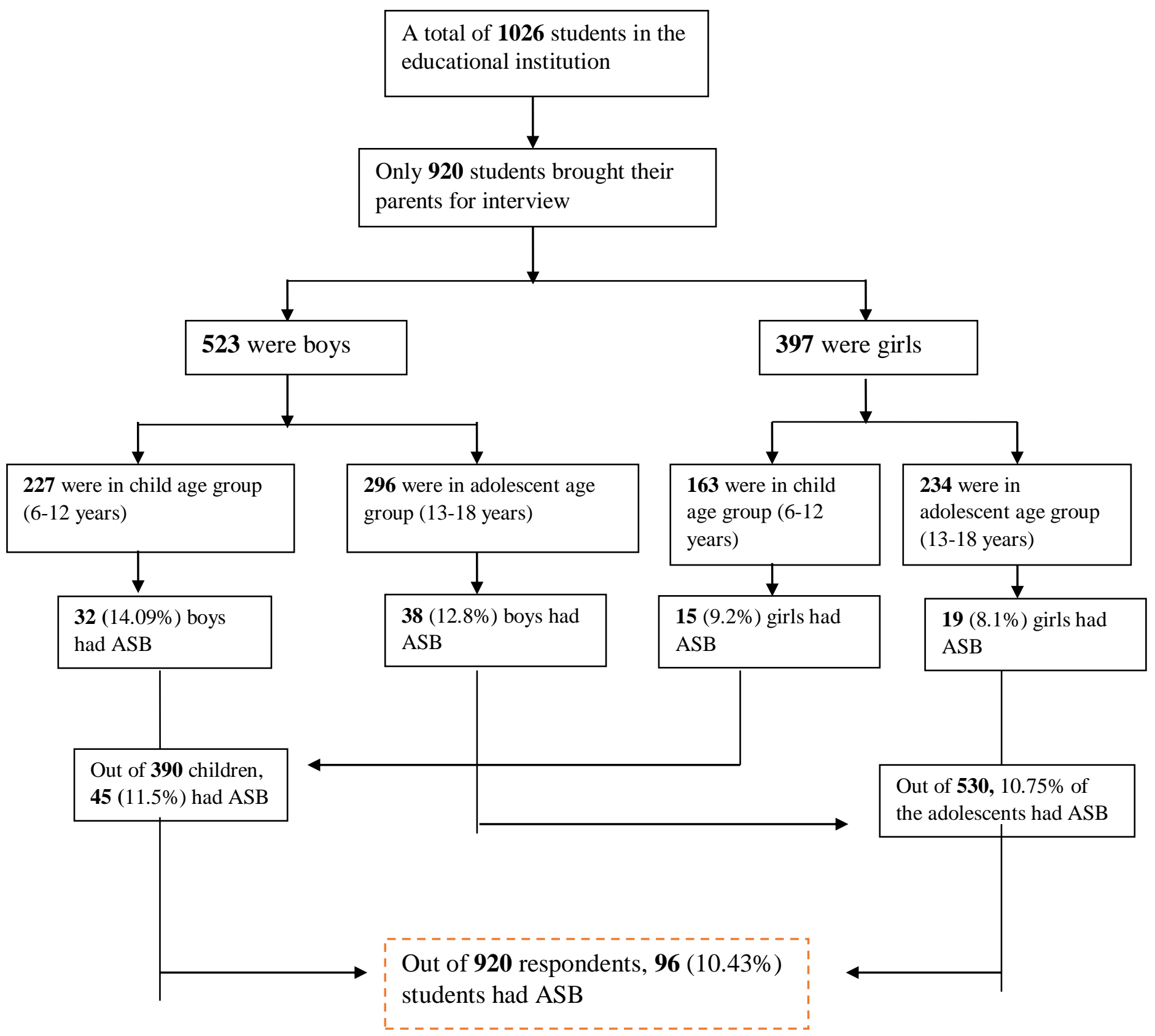




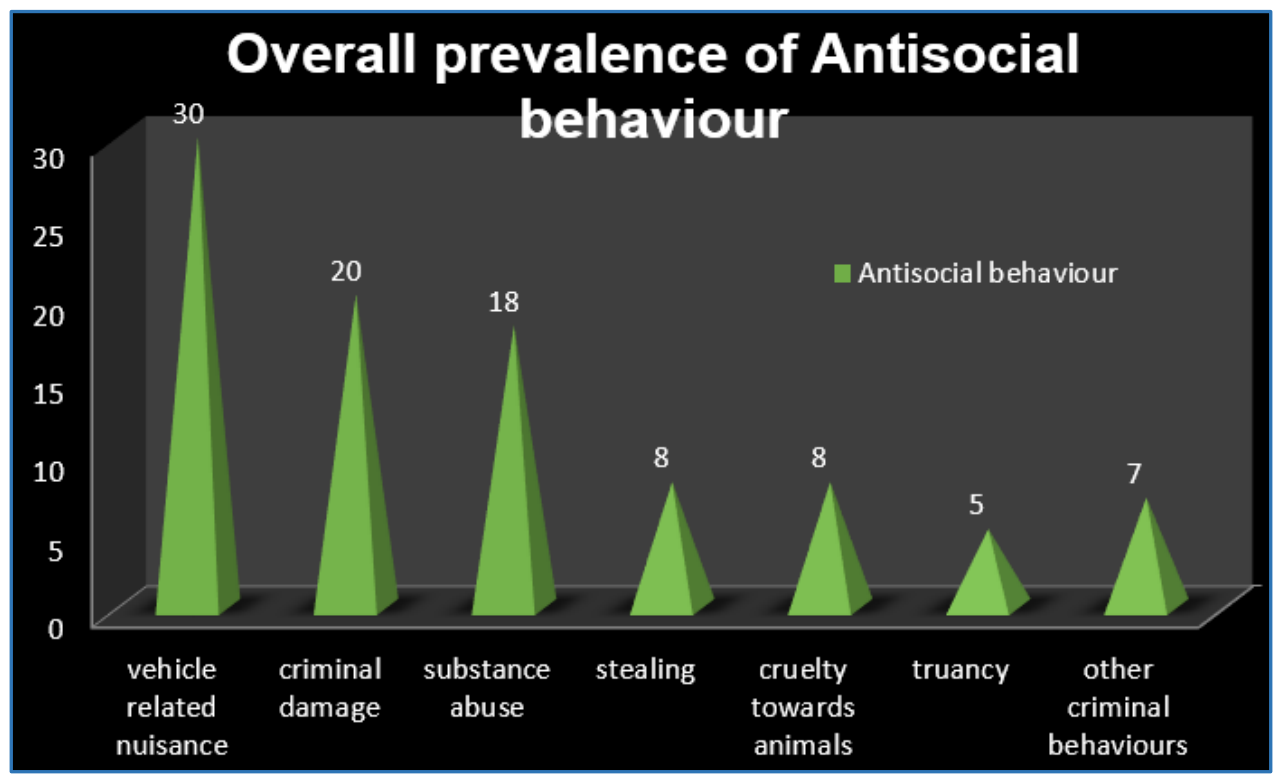

\begin{tabular}{|c|c|c|c|c|}
\hline \multicolumn{4}{|c|}{ Antisocial Behaviour } & Percentage \\
\hline \multirow{2}{*}{$\begin{array}{l}\text { Vehicle Related } \\
\text { Nuisance }\end{array}$} & 30 & Adolescent & 17 & \multirow{2}{*}{$30 / 920=3.2 \%$} \\
\hline & & Children & 13 & \\
\hline \multirow{2}{*}{$\begin{array}{l}\text { Criminal } \\
\text { Damaging }\end{array}$} & 20 & Adolescents & 8 & \multirow{2}{*}{$20 / 920=2.17 \%$} \\
\hline & & Children & 12 & \\
\hline \multirow{2}{*}{$\begin{array}{c}\text { Substance Abuse } \\
\text { (Smoking, } \\
\text { Alcohol, Drug } \\
\text { Abuse) }\end{array}$} & 18 & Adolescents & 14 & \multirow[b]{2}{*}{$18 / 920=1.9 \%$} \\
\hline & & Children & 4 & \\
\hline \multirow{2}{*}{ Stealing } & 8 & Adolescents & 3 & \multirow{2}{*}{$8 / 920=0.86 \%$} \\
\hline & & Children & 5 & \\
\hline \multirow{2}{*}{$\begin{array}{c}\text { Cruelty Towards } \\
\text { Animals }\end{array}$} & 8 & Adolescents & 3 & \multirow{2}{*}{$8 / 920=0.86 \%$} \\
\hline & & Children & 5 & \\
\hline \multirow{2}{*}{ Truancy } & 5 & Adolescents & 2 & \multirow{2}{*}{$6 / 920=0.65 \%$} \\
\hline & & Children & 4 & \\
\hline \multirow{2}{*}{$\begin{array}{l}\text { Other Criminal } \\
\text { Behaviours }\end{array}$} & 7 & Adolescents & 4 & \multirow{2}{*}{$6 / 920=0.65 \%$} \\
\hline & & Children & 2 & \\
\hline \multicolumn{5}{|c|}{ Table 1. Showing Prevalence of ASB in Both Groups } \\
\hline
\end{tabular}

\begin{tabular}{|c|c|c|c|c|c|}
\hline \multirow[t]{2}{*}{ Males } & Adolescents & 38 & Total & $70 / 96$ & $72.96 \%$ \\
\hline & Children & 32 & & & \\
\hline \multirow[t]{2}{*}{ Females } & Adolescents & 19 & Total & $34 / 96$ & $35.4 \%$ \\
\hline & Children & 15 & & & \\
\hline & $\begin{array}{l}\text { ble 2. Shou } \\
\text { from } 1\end{array}$ & h & $\begin{array}{l}\text { Ger } \\
\text { Gro }\end{array}$ & ences & \\
\hline
\end{tabular}

\begin{tabular}{|c|c|c|c|c|}
\hline & Males & Females & Total & \\
\cline { 1 - 4 } $\begin{array}{c}\text { Peer Group } \\
\text { Influence }\end{array}$ & $\begin{array}{c}213 \\
(24.5 \%)\end{array}$ & $45(4.89 \%)$ & $258(28.04 \%)$ & \\
\cline { 1 - 4 } $\begin{array}{c}\text { Poor } \\
\text { Parenting }\end{array}$ & $\begin{array}{c}33 \\
(3.5 \%)\end{array}$ & $198(21.6 \%)$ & $233(17.1 \%)$ & \\
\hline $\begin{array}{c}\text { Media } \\
\text { Influence }\end{array}$ & $\begin{array}{c}52 \\
(26.9 \%)\end{array}$ & $45(21.5)$ & $97(24.1)$ & \\
\hline $\begin{array}{c}\text { Family } \\
\text { Socio- } \\
\text { economic } \\
\text { Status }\end{array}$ & 33 & $62(29.7)$ & $95(23.6)$ & \\
\cline { 1 - 4 } $\begin{array}{c}\text { Religious/ } \\
\text { Moral } \\
\text { Decadence }\end{array}$ & $\begin{array}{c}22 \\
(11.4 \%)\end{array}$ & $48(23.0)$ & $70(17.4)$ & \\
\hline \multicolumn{4}{|c|}{ Table 3. Perceived Factors Influencing } \\
\hline \multicolumn{4}{|c|}{ Antisocial Behaviour as per Parents } \\
\hline
\end{tabular}

\section{DISCUSSION}

The overall prevalence of antisocial behaviours in both age groups were $10.43 \%$; where males $(72.96 \%)$ predominate over females (35.4\%) which was found significant statistically $(\mathrm{p}<0.05)$. Vehicle related nuisance with inappropriate vehicle (3.2\%) use was found to be most common form of antisocial behaviour followed by damaging things, which was found more prevalent among children than adolescents. The third most common ASB was substance abuse where adolescents predominate children, where smoking was found to be the most common form of substance abuse, followed by alcohol and other drug abuse without parents' permission. Majority of the parents [213 (24.7\%)] opine that peer group influence predisposes children and adolescents to antisocial behaviour which affects boys more than girls; many others say that [198 (21.6\%)] poor parenting style affects girls significantly than boys; media influences the causes for antisocial behaviour in both sexes of children and adolescent age group (Table 3).

The present study has demonstrated the existence of antisocial behaviours such as vehicle related nuisance, alcoholism, smoking, and drug abuse among children and adolescents in secondary schools in Shimoga district. Adolescents and children whose parents are poor are usually associated with bad peers whereas the reverse is the case for children and adolescents whose parents are rich. The later grow up without being a deviant or being involved in any antisocial behaviour (Roberts, 1981).

Vehicle-related nuisance \& inappropriate vehicle use was the most common type in our study; may include inconvenient/illegal parking, Car repairs on the street/in gardens, setting vehicles alight, joyriding, racing cars off-road, motorcycling, cycling/skateboarding in pedestrian areas/footpaths. Substance abuse, especially smoking was found to be the most prevalent form of antisocial behaviour among children and young adults. The result is anticipated in that it is easier for an adolescent to retire to a corner of the road or bush to smoke than to drink alcohol (Nwankwo, 2006b). ${ }^{17,18}$ While at school, smoking is considered by boys as sign of manhood or status. This transit flirtation with smoking may later become a permanent habit, unless quickly checked (Christie-smith, 1999; Hins et al, 1998). Teenagers 
also often start smoking in imitation of the older people who smoke. ${ }^{19,20}$ Elegbeleye (1997) and Nwankwo et al (2008) has asserted that peer smoking is clearly related to peer influence which is extremely important in the development of smoking habit, particularly during the teenage and college years and later they may continue if it is an accepted and admired habit within their social group.

The study also identified truancy as another major antisocial behaviour exhibited by the adolescents. Truancy has been associated with and often regarded as one of the effects, off shoots and expressions of negative emotions (anger, envy, greed, fear, hatred, shame, blame, regret, resentment, hostility, worry, jealously, etc.), which interfere and hamper one's mental, social, and emotional well beings (Nwankwo, 2006 a). The major problems observed in all children, emotional and psychological needs, were identical. The result is many needs of children are not fulfilled. They then become frustrated and may lend their frustration in various ways, such as truancy which is typically seen as a misbehaviour. ${ }^{2}$

However, the inability of most adolescents to resolve emotional or psychological conflicts early in life, during the course of fulfilling their normal development tasks, may lead to negative consequences later in life. One has to accomplish, resolve, and master developmental tasks that arise in certain period of individual development if one is to become successful, normal and well-adjusted person in the society. Accordingly, successful achievement, satisfaction, resolution of these tasks will lead to happy satisfying period of life, while failure leads to unhappiness, disapproval, non-recognition, frustration, stress, substance abuse, crime, truancy, delinquency, many bad lifestyles, and behaviours (Nwankwo, 2006a).2.16

Results from table 3 indicate that poor parenting style is a major cause of antisocial behaviour among adolescent girls. Parenting style is a serious factor affecting adolescent future lifestyle. When a child is modelled in a right way and at the right time, there are strong assurances that he or she may grow up to be a good citizen. Family management practices such as marital breakdown, different caretakers, harsh and inconsistent disciplines or multiple mothering in early childhood are important factors in developing aggressive and antisocial behaviour in adolescents later in life (Ary et al 1999a, b; Marttunen et al 2007; Loeber and StouthamerLoeber, 1986; MacDonald, 1985) 6, 21

Family economic status was also implicated in this study as another factor of influence in adolescent antisocial behaviour (Table 2). To this end, Nwankwo (2004) had demonstrated that poverty which is deeply rooted in Africa where the parents were not being able to meet up with their obligations to their children, thereby pushing their children to conduct themselves in manners that society considers abnormal or antisocial is one of the main causes. ${ }^{2}$

A longitudinal study by Terrie EM et al finds no difference in the causes of antisocial behaviour between the genders and no evidence to support the hypothesis that females must pass a higher threshold of risk to develop a disorder. The genders differ most on the more serious life course-persistent pattern of antisocial behaviour. This pattern is rare in females, with a ratio of 10 males to one female in the study cohort. Majority of females who engage in antisocial behaviour fit the adolescence-limited pattern and the gender ratio here is 1.5 males to 1 female. Individual neurodevelopment factors-specifically, neurocognitive deficits, uncontrolled temperament, weak constraint and hyperactivity are identified as key to understanding lifecourse persistent antisocial behaviour. The fact that these neurodevelopment risk factors occur more frequently in males is used to explain the male preponderance of this pattern of antisocial behaviour.22

Prevalence rates of antisocial behaviour ultimately depends on the type of incident being examined, geographical location, culture, family characteristics, socio-economic setting, sampling procedure, and diagnostic criteria used (Iloeje, 1992; Boyle et al 1996). About 30\%-45\% of child consultations including community child health had referred to the physician for behavioural disturbances (NICE guidelines, 2013). It has been reported to be as high as $10 \%$ $26 \%$ in both developed and developing countries (Abiodun, 1993; Rutter, 1973). In a study of 240 students in four schools in Kanke, 27\% rate was reported among adolescents (Sujit, Vinod \& Pushpal, 2006). In South East Nigeria, cultism $(68.7 \%)$ is the major antisocial behaviour among secondary school students, followed by smoking (13.4\%), then truancy (12.3\%), alcoholism (3.0\%), and lastly drug abuse $(2.6 \%)$ (Nwankwo et al, 2000). The prevalence of antisocial behaviour done by the Australian Institute of Family Studies showed that the most prevalent types of antisocial behaviour in early adolescence were fighting (32\%), alcohol use (25\%), theft (16\%), and property damage (14\%) (Harradine, Kodz, Lemetti \& Jones, 2004; Hayes, 2004). These behaviours continued into mid-adolescence along with high rates of cigarette use (28\%), and truancy (27\%) (Harradine, Kodz, Lemetti \& Jones, 2004; Hayes, 2004). In late adolescence alcohol use (84\%), truancy (43\%), cigarette use (39\%), fighting (23\%), property damage (20\%), Marijuana use (19\%), and driving a car without permission (15\%) were the most common types of antisocial behaviour (Harradine, Kodz, Lemetti \& Jones, 2004; Hayes, 2004).23,24

Another study by Diwe K et al (2016) to estimate the gender differences in prevalence of conduct disorders in South East Nigeria was found that two hundred and eighty $(69.7 \%)$ of the respondents had committed at least one form of antisocial behaviour. Males, 150 (77.7\%) had higher prevalence of antisocial behaviour compared to their female counterparts, 130 (62.2\%). This difference in prevalence was statistically significant, $(\chi 2=10.71, \mathrm{df}=1, \mathrm{p}=0.001)$. The most prevalent antisocial behaviour in both sexes was stealing males, 140 (72.5\%); females 120 (57.4\%). This was followed by cultism 67 (34.7\%), smoking 65 (33.6\%) and alcohol use $62(31.1 \%)$ in males. In females, it was sexual promiscuity 60 (28.7\%), cultism $50(23.9 \%)$ and clubbing 35 (16.7\%). This variation in pattern was not statistically significant ( $p$ $>0.05) \cdot 13,24$

Common factors perceived by respondents that influenced antisocial behaviour were peer group pressure 208 (51.7\%), poor parenting, 149 (37.1\%), media/internet influence, 97 (24.1\%) and family socioeconomic status 95 (23.6\%). In males, it was peer group pressure, 113 (58.5\%), poor parenting, 60 (31.1\%) and media/internet influence, 52 $(26.9 \%)$, while in females it was peer group pressure 95 (45.5\%), poor parenting $89(42.6 \%)$ and family socioeconomic status $62(29.7 \%)$. This variation in perceived causal factors was statistically significant, $(\chi 2=9.54, \mathrm{df}=4$, 
$\mathrm{p}=0.002$ ). The commonest perceived consequence of antisocial behaviour in females was poor academic performance 189 (80.9\%) while it was increased criminal activities among their male counterparts 120 (62.2\%). This variation was not statistically significant, $p>0.05$.

\section{Implications for Reducing Adolescent ASB}

Results from this have implications for treating antisocial youth. First, it is important that professionals not only have to assess adolescent's relationships and family dynamics, but also aspects of the community in which they reside as well. Secondly, social workers should also emphasise the importance of other predictors of ASB including adolescent's temperament, socioeconomic status, low academic performance in conjunction with school failure, and parental criminality or mental health problems as well (Gentle-Genitty 2010). Finally, the number of accumulated risk factors appears to be more important than what types of risk factors youth face (De-Mey et al 2009). ${ }^{25}$

\section{CONCLUSIONS}

In our study, vehicle-related nuisance was found to be the most common antisocial behaviour which results in risk of accidents leading to medical and social problems. Other ASBs were criminal damages and substance abuse which can lead to legal issues. Identifying factors associated with adolescent risk behaviour is critical for developing effective treatment strategies. Early identification and intervention will minimise the risk of progression to more serious criminal behaviours later in life. We hope that this paper will make policy makers and educators realise the need to enact and enforce appropriate policies that will curtail the risk of antisocial behaviour among children and adolescents.

\section{REFERENCES}

1. Anderson DA. The aggregate burden of crime. Journal of Law and Economics 1999;42(2):611-642.

2. Nwankwo BO. Mental and Emotional Health. Owerri: Megasoft publishers 2006a. ISBN978-36223-4.

3. Robert A. Mental health history timelines. Middlesex University. $1981 . \quad$ Retrieved on 28/3/2010@8p.m.http//studymre.org.uk/mhhtim.htm.

4. Hayes N, Minardi H. Psychology and Ageing. Chap 7. In: Woodrow, P, ed. Ageing-issues for physical, psychological and social health. London: Whurr Publishers Ltd 2002:93114

5. Hayes N, Minardi H. Abnormal psychology in old age. Chap 8. In: Woodrow P, ed. Ageing- issues for physical, psychological and social health. London: Whurr Publishers Ltd 2002:115-38.

6. Loeber R, Stouthamer-Loeber M. Family factors as correlates and predictors of Juvenile conducts problems and delinquency, in crime and justice: an annual review of research. University of Chicago 1986;(7):29-149.

7. Bell RQ. Age-specific manifestations in changing psychological risks. In: Faren DC, McKinney JD, eds. Risk in intellectual and psychological development. Orlando: Academic Press 1986:169-85.

8. Ary DV, Ducan A, Biglan A, et al. Development of adolescent problem behaviour. J Abnorm Child Psychol 1999;27(2):141-50.
9. Ary DV, Duncan TE, Duncan SC, et al. Adolescent problem behaviour: the influence of parents and peers. Behav Res Therapy 1999;37(3):217-30.

10. Robins L. Changes in conduct over time. In: Faran DC, McKinney JD eds. Risk in intellectual and psychosocial development. Orlando, FL: Academic Press 1986:227-59.

11. Rutter M, Giller H. Juvenile delinquency: trends and perspectives. UK: Middlesex Pengiun 1983.

12. Bandura A. Self efficacy: towards a unifying theory of behaviour change. Psychol Rev 1977;84(2):191-215.

13. Diwe K, Aguocha C, Duru C, et al. Gender differences in prevalence and pattern of conduct disorder among adolescent secondary school students in south east Nigeria. Asian Journal of Social Sciences \& Humanities 2016:5(1):49-58.

14. Achenbach TM, Rescorla LA. Child behaviour checklist (CBCL- $1 \frac{1}{2}$ - 5 years). Manual for the ASEBA preschool forms and profiles. Burlington, VT: University of Vermont Department of Psychiatry 2000. ISBN 0-938565-68-0.

15. Achenbach TM, Rescorla LA. Child behaviour checklist (CBCL) 6-18 years. Manual for the ASEBA School-Age Forms and Profiles. Burlington, VT: University of Vermont, Research Center for Children, Youth, and Families 2001. ISBN 0-938565-73-7.

16. American psychiatric association. Diagnostic and statistical manual of mental disorders, $5^{\text {th }}$ edn. DSM-5. United states of America 2013;302:423-59.

17. Nwankwo BO. Chemical substances and human behaviour. Owerri: Omni Publishers 2006. ISBN97838432-0-6.

18. Nixon J, Blandy S, Hunter C, et al. Developing good practice in tackling antisocial behaviour in mixed tenure areas. Sheffield: Sheffield Hallam University 2003.

19. Christie-Smith D. Smoking-cessation programs need to target college students. Am J Health Syst Pharm 1999;56(5):415-6.

20. Hines D, Fretz AC, Nollen NL. Regular and occasional smoking by college students: personality attributions of smokers and nonsmokers. Psychol Rep 1998;83(3 Pt 2):1299-306.

21. Marttunen MJ, Henriksson MM, Lnngvist JK. Antisocial behaviour in adolescent suicide. Acta Psychiatrica Scandinavica 2007;89:167-73.

22. Moffitt TE. Adolescence-limited and life-course-persistent antisocial behaviour: a developmental taxonomy. Psychol Rev 1993;100(4):674-701.

23. Boyle MH, Offord DR, Racine $\mathrm{Y}$, et al. Identifying thresholds for classifying childhood psychiatric disorder: issues and prospects. J Am Acad Child Adolesc Psychiatry 1996;35(11):1440-8.

24. Iloeje So, Meme J. Rutter's behaviour scale (B2) for children (teacher's scale): Validation and standardization for use on Nigerian children. J Trop Pediatr 1992;38(5):235-9.

25. De Mey W, Coussee F, Vandenbroeck M, et al. Social work and parents support in reaction to children's antisocial behaviour: constructions and effects. International Journal of Social Welfare 2006;18(3):299-306. 